\title{
The Prevalence and Characteristics of Thoracic Outlet Syndrome in High School Baseball Players
}

\author{
Kenichi Otoshi' ${ }^{1}$, Shinichi Kikuchi², Kinshi Kato², Ryohei Sato ${ }^{2}$, Takahiro Igari², Takahiro Kaga1, \\ Hiroaki Shishido ${ }^{2}$, Shinichi Konno ${ }^{2}$, Ryuji Koga ${ }^{3}$, Kozo Furushima ${ }^{3}$, Yoshiyasu Itoh ${ }^{3}$
}

${ }^{1}$ Department of Sports Medicine, Fukushima Medical University School of Medicine, Fukushima, Japan

${ }^{2}$ Department of Orthopaedic Surgery, Fukushima Medical University School of Medicine, Fukushima, Japan

${ }^{3}$ Keiyu Orthopaedic Hospital, Tatebayashi, Japan

Email: kootoshi@fmu.ac.jp

How to cite this paper: Otoshi, K., Kikuchi, S., Kato, K., Sato, R., Igari, T., Kaga, T., Shishido, H., Konno, S., Koga, R., Furushima, K. and Itoh, Y. (2017) The Prevalence and Characteristics of Thoracic Outlet Syndrome in High School Baseball Players. Health, 9, 1223-1234.

https://doi.org/10.4236/health.2017.98088

Received: April 11, 2017

Accepted: August 22, 2017

Published: August 25, 2017

Copyright (c) 2017 by authors and Scientific Research Publishing Inc. This work is licensed under the Creative Commons Attribution International License (CC BY 4.0).

http://creativecommons.org/licenses/by/4.0/

\begin{abstract}
Thoracic outlet syndrome (TOS) is one of the common neurovascular disorders of the upper extremities, and the compression or traction of the brachial plexus is the main pathology. We hypothesized that baseball players are more likely to be affected by TOS compared with other overhead-throwing athletes because of strenuous use of their throwing arm. The purpose of this study was to investigate the prevalence and clinical characteristics of TOS in high school baseball players. One thousand two hundred eighty-eight high school baseball players were included in this study. The prevalence of symptomatic TOS and its association to disorders of the upper extremities were investigated. The prevalence of symptomatic TOS was $32.8 \%$. Age- and position-adjusted logistic regression analysis revealed that subjects with symptomatic TOS were at significantly higher risk of shoulder and/or elbow pain (odds ratio [OR]: 1.96, 95\% confidence interval [CI]: 1.50 - 2.58) and a higher recurrence rate of shoulder and/or elbow pain during the previous season (OR: 2.38, 95\% CI: 1.87 - 3.04). As for physical findings, subjects with symptomatic TOS were also at significantly higher risk of MUCL tenderness (OR: 2.53, 95\% CI: 1.83 3.50), positive milking maneuver, (OR: $2.63,95 \%$ CI: 1.78 - 3.91), positive subacromial impingement sign (OR: 1.92, 95\% CI: 1.20 - 3.07), and positive posterior impingement sign (OR: $2.34,95 \%$ CI: 1.67 - 3.28) compared to the subjects without symptomatic TOS. It is necessary to recognize that TOS is not a rare pathology in overhead-throwing athletes, especially baseball players, and that players with symptomatic TOS are at significantly higher risk of shoulder/elbow pain.
\end{abstract}




\section{Keywords}

Thoracic Outlet Syndrome, Baseball Players, Prevalence

\section{Introduction}

Thoracic outlet syndrome (TOS), first described by Peet and associates [1], has been characterized as upper extremity symptoms caused by compression of the neurovascular structures at the thoracic outlet lesion.

Several congenital and acquired factors have been reported as causes of TOS. Cervical rib and fibrous band have been the most common congenital cause associated with TOS [2] [3] [4] [5] [6], and anomalies of first rib and cervical muscle variants have also been considered as possible causes [7] [8] [9] [10].

In addition to the congenital factors, several potential sites of compression at the thoracic outlet lesion have previously been reported. At the interscalene triangle, the neurovascular bundle is vulnerable to entrapment between the anterior and middle scalene muscles (scalenus anticus syndrome) [11] [12] or between the anterior scalene muscle and the clavicle [13]. Costoclavicular level neurovascular compression secondary to hyperabduction of the arm was first described by Lewis and Pickering in 1934, and this condition was defined as costoclavicular syndrome in 1943 [14] [15]. Neurovascular compression also occurs at the subcoracoid space by the stretched overlying pectoralis minor muscle when the arm is brought overhead. This condition was first described by Wright in 1945 as "hyperabduction syndrome", in which neurovascular bundle was occluded by the overlying pectoralis minor muscle [16]. Sanders RJ described the several characteristic findings of "neurogenic pectoralis minor syndrome", such as no history of trauma, absent of occipital headache and neck pain, and minimal or no response to the provocative test of TOS [17] [18].

Athletic activity using the upper extremities is also associated with the development of TOS, and there have been many reports of athletes with neurogenic and vascular TOS [19] [20] [21] [22] [23]. Vigorous repetitive overhead use of the upper extremities required in most overhead-throwing sports may lead to loss of shoulder girdle stability as well as hypertrophy of scalene and pectoralis minor muscles, which can induce neurovascular compression at these sites, especially congenital abnormalities.

Among the several overhead-throwing sports, players in baseball are considered to be at highest risk of developing TOS. Several cases of serious vascular TOS in Major League Baseball players have previously been reported [24]. Tullos et al. reported the first case of axillary artery occlusion in a major league pitcher in 1972 [25]. They postulated that repetitive transient occlusion of the axillary artery by the stretched pectoralis minor muscle was the main cause of this pathology. Axillary-subclavian vein effort thrombosis (Paget-Schroetter syndrome) has also been considered as the most frequently encountered vascular disorder [26], and there have been two cases of venous thrombosis in major league pitchers 
[5] [24]. Since the incidence rate of vascular TOS (arterial or venous) has been reported to be less than 5\% of all TOS [27] [28] [29], it is estimated that many overhead-throwing athletes may be affected with neurogenic TOS.

The diagnosis of TOS, especially neurogenic TOS, is often considered to be difficult because the clinical presentation of TOS is highly variable and many pathognomonic signs or symptoms to confirm this syndrome [30]. Furthermore, associated double-crush syndrome and hypersensitivity of the involved upper extremities can further confuse the clinical presentation. Therefore, there have only been a few reports that describe the prevalence of TOS [31]. In the working population, Sällström et al. described that approximately $18 \%$ of their subjects had induced neurovascular symptoms by using the TOS provocation test [32] [33]. As for overhead athletes, only one report describes the prevalence of TOS in elite volleyball players, ranging from $11 \%$ to $27 \%$ [34]. We hypothesized that baseball players might be more vulnerable to TOS compared with other overhead-throwing athletes because of the strenuous use of their throwing arm.

The purpose of this study was to investigate the prevalence of TOS in baseball players and clarify their clinical implications using the large epidemiologic data from medical checkups in high school baseball players.

\section{Materials and Methods}

Of the 1345 high school baseball players who participated in the annual medical checkups, 1288 players without missing data were included in this study. The subjects were all male gender and aged 15 to 17 years old (Table 1), and the players who had an operation most recently, or who were in treatment for traumatic injury of upper extremity were excluded. This study was comprised of

Table 1. Sociodemographic data of the subjects.

\begin{tabular}{|c|c|c|}
\hline \multirow{3}{*}{ Age } & 15 years & 165 \\
\hline & 16 years & 640 \\
\hline & 17 years & 481 \\
\hline Mean age (years) & \multicolumn{2}{|c|}{$16.2 \pm 0.7$} \\
\hline \multirow{2}{*}{ Gender } & Mail & 1288 \\
\hline & Female & 0 \\
\hline \multirow[t]{3}{*}{ Mean age of initiation into baseball (years) } & \multicolumn{2}{|c|}{$9.6 \pm 2.2$} \\
\hline & Pitcher & 292 \\
\hline & Catcher & 135 \\
\hline \multirow[t]{4}{*}{ Main position } & Infielder & 480 \\
\hline & Outfielder & 356 \\
\hline & Others & 25 \\
\hline & Days & $6.5 \pm 0.6$ \\
\hline Total amount of practice per week & Hours & $27.2 \pm 7.5$ \\
\hline
\end{tabular}


two items: a self-completed questionnaire and a physical examination. A self-completed questionnaire form was distributed to the subjects before the medical checkup and was collected on the day of the checkup. Items on the questionnaire included experience of previous neurovascular symptoms such as a sensation of heaviness, numbness, fatigue, or coldness of their throwing arm during or after throwing or exercise.

Experience and number of recurrence of shoulder and/or elbow pain during the previous season were also investigated.

As for the physical findings, the three-minute elevated arm stress test (EAST) described by Roos was used as the provocation test for TOS [10]. In the EAST, the subjects were instructed to abduct the arms to 90 degrees to the thorax with their forearms flexed, also at 90 degrees, and shoulders braced backwards. The subjects then clenched and opened their fists at a moderate speed for three minutes (Figure 1).

During the test, induced symptoms such as heaviness, numbness, early fatigue, hot flushes, and coldness, and the side on which the symptoms occurred were registered. In addition, the sustainable period at which the player was able to continue the test was also measured to evaluate the severity of TOS. Tenderness of the medial ulnar collateral ligament (MUCL), elbow valgus stress test (Milking maneuver) [35], subacromial impingement sign (positive Neer test), and posterior impingement sign [36] were also investigated to assess the common shoulder and elbow joint disorders induced by throwing motion.

In our criteria, "symptomatic TOS" was defined as when the subjects fulfilled the following two conditions: 1) previous experience of subjective neurovascular symptoms; and 2) positive EAST result in their throwing arm.

The relationships between symptomatic TOS and upper extremity pain (subjective pain during throwing, MUCL tenderness, and pain induced by stress test) were examined by the chi-square test, and odds ratio (OR) and $95 \%$ confidence intervals $(95 \% \mathrm{CI})$ were calculated by age- and position-adjusted logistic regression analysis. $\mathrm{P}$ values of less than 0.05 were considered to indicate statistical significance. Participants with complete data were entered into the primary

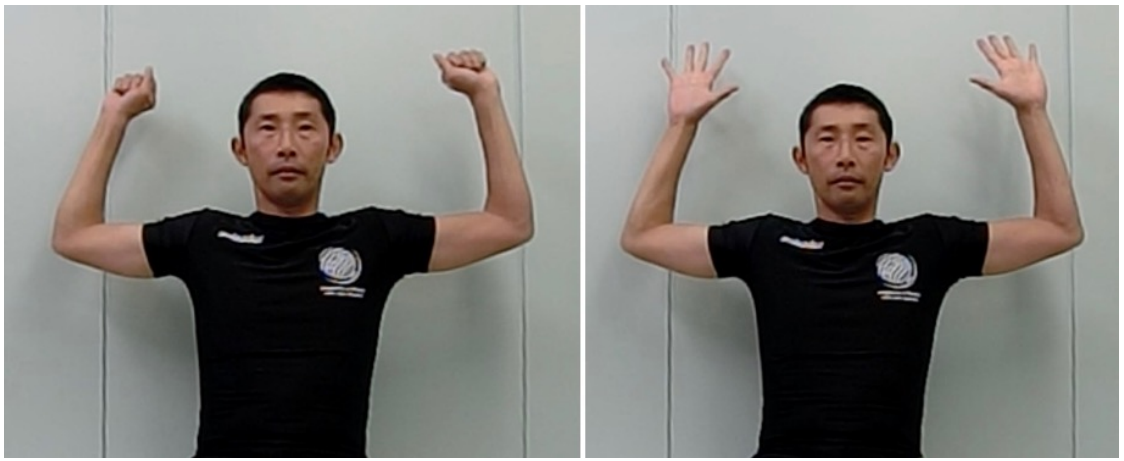

The subjects were instructed to abduct the arms at 90 degrees to the thorax with the forearms flexed, also at 90 degrees, and shoulders braced backwards. The subjects then clenched and opened their fists at a moderate speed for three minutes.

Figure 1. Three-minute elevated arm stress test (EAST). 
analysis. All analyses were conducted using JMP version 10.0.2 (SAS Institute, Cary, NC, USA). The Research Ethics Committee of our institute approved the study protocol, and written informed consent was obtained from all subjects.

\section{Result}

\subsection{Experience of Subjective Neurovascular Symptoms in the Throwing Arm}

Of the 1288 subjects, $622(48.3 \%)$ had previously experienced at least one neurovascular symptom in their throwing arm. By type of symptom, there were: 403 reports of (31.3\%) of heaviness; $386(30.0 \%)$ of numbness; $164(12.7 \%)$ of fatigue; and 113 (8.8\%) of coldness. There were no significant differences among the player's positions; however, pitchers had a slightly higher prevalence compared with players of other positions.

\subsection{EAST Results}

EAST results were shown in Table 2. Of the 1288 subjects, 1008 (78.3\%) had at least one symptom induced during EAST. The most commonly induced symptom was heaviness, reported by $49.4 \%$ of the subjects, while $21.6 \%$ experienced numbness, $15.0 \%$ hot flush, $10.1 \%$ pain, $8.9 \%$ fatigue, and $4.4 \%$ coldness. With regards to the side on which the symptoms occurred by EAST, $40 \%$ of the subjects had symptoms induced bilaterally, with a more common occurrence in the throwing arm (25\%) than in the non-throwing arm (13\%). As for the sustainable period at which the player was able to continue the EAST, $34.3 \%$ of the subjects found it hard to continue the EAST for more than 30 seconds, and $4.7 \%$ of the subjects were able to continue for less than 15 seconds. There were no significant differences among the player's positions in overall prevalence, involved side, and sustainable time.

Table 2. The EAST test results.

\begin{tabular}{|c|c|c|}
\hline \multirow{2}{*}{ EAST result } & Negative & $280(21.7 \%)$ \\
\hline & Positive & $1008(78.3 \%)$ \\
\hline \multirow{7}{*}{ Induced symptoms by EAST } & Heaviness & $636(49.4 \%)$ \\
\hline & Numbness & $278(21.6 \%)$ \\
\hline & Hot flush & $193(15.0 \%)$ \\
\hline & Pain & $130(10.1 \%)$ \\
\hline & Fatigue & $114(8.9 \%)$ \\
\hline & Coldness & $57(4.4 \%)$ \\
\hline & Others & $27(2.1 \%)$ \\
\hline \multirow{3}{*}{$\begin{array}{c}\text { The side on which the symptoms } \\
\text { occurred by EAST }\end{array}$} & Bilateral side & $518(40.2 \%)$ \\
\hline & Throwing side only & $327(25.4 \%)$ \\
\hline & Non-throwing side only & $163(12.7 \%)$ \\
\hline \multirow{3}{*}{$\begin{array}{l}\text { The sustainable period at which the } \\
\text { player was able to continue the EAST }\end{array}$} & Severe (less $15 \mathrm{sec}$ ) & $60(4.7 \%)$ \\
\hline & Moderate (15 - $30 \mathrm{sec})$ & $381(29.6 \%)$ \\
\hline & Mild (over $30 \mathrm{sec}$ ) & $567(44.0 \%)$ \\
\hline
\end{tabular}

EAST: elevated arm stress test. 


\subsection{The Prevalence of Symptomatic TOS (Our Criteria)}

Of the 622 subjects who experienced neurovascular symptoms in their throwing arm, 497 subjects exhibited positive EAST results (232 bilaterally, 190 in the throwing arm, and 75 in the non-throwing arm). According to our criteria, 422 (32.8\%) of the subjects met the definition of "symptomatic TOS". There was no significant difference among player position, although there was a slightly higher prevalence in pitchers.

\subsection{The Influence of Symptomatic TOS on the Throwing Disorders of the Upper Extremities}

Shoulder and/or elbow pain were significantly higher in the subjects with symptomatic TOS compared to those without. The prevalence of positive MUCL tenderness, milking maneuver, subacromial and posterior impingement sign were also significantly higher in the subjects with symptomatic TOS compared to those without (Table 3).

Table 3. Clinicodemographic variables according to presence of symptomatic TOS.

\begin{tabular}{|c|c|c|c|c|c|c|}
\hline & & & $\begin{array}{c}\text { Total } \\
(\mathrm{n}=1288)\end{array}$ & $\begin{array}{l}\text { Subjects with } \\
\text { symptomatic } \\
\text { TOS }(\mathrm{n}=422)\end{array}$ & $\begin{array}{l}\text { Subjects without } \\
\text { symptomatic } \\
\text { TOS }(\mathrm{n}=866)\end{array}$ & P-value \\
\hline \multirow{3}{*}{\multicolumn{2}{|c|}{ Age(years) }} & 15 & $165(12.8 \%)$ & $33(7.9 \%)$ & $132(15.2 \%)$ & \multirow{3}{*}{$<0.001$} \\
\hline & & 16 & $640(49.8 \%)$ & $195(46.4 \%)$ & $445(51.4 \%)$ & \\
\hline & & 17 & $481(37.4 \%)$ & $192(45.7 \%)$ & $289(33.4 \%)$ & \\
\hline \multirow{5}{*}{\multicolumn{2}{|c|}{ Main position }} & Pitcher & $292(22.7 \%)$ & $106(25.1 \%)$ & $186(21.5 \%)$ & \multirow{5}{*}{0.577} \\
\hline & & Catcher & $135(10.5 \%)$ & $41(9.7 \%)$ & $94(10.9 \%)$ & \\
\hline & & Infielder & $480(37.3 \%)$ & $148(35.1 \%)$ & $332(38.3 \%)$ & \\
\hline & & Outfielder & $356(27.6 \%)$ & $119(28.2 \%)$ & $237(27.4 \%)$ & \\
\hline & & Others & $25(1.9 \%)$ & $8(1.9 \%)$ & $17(2.0 \%)$ & \\
\hline \multirow{4}{*}{$\begin{array}{l}\text { Positive subjective } \\
\text { symptom during the } \\
\text { previous season }\end{array}$} & \multirow{4}{*}{$\begin{array}{l}\text { Reccurence of shoulder/elbow } \\
\text { pain }\end{array}$} & Negative & $423(32.8 \%)$ & $97(23.0 \%)$ & $326(37.6 \%)$ & \multirow{2}{*}{$<0.001$} \\
\hline & & Positive & $865(67.2 \%)$ & $325(77.0 \%)$ & $540(62.4 \%)$ & \\
\hline & & Negative & $707(54.9 \%)$ & $168(39.8 \%)$ & $539(62.2 \%)$ & \multirow{2}{*}{$<0.001$} \\
\hline & & Positive & $581(45.1 \%)$ & $254(60.2 \%)$ & $327(37.8 \%)$ & \\
\hline \multirow{8}{*}{$\begin{array}{l}\text { Abnormality of Physical } \\
\text { findings }\end{array}$} & \multirow{2}{*}{ MUCL tenderness } & Negative & $1103(85.6 \%)$ & $327(77.5 \%)$ & $776(89.6 \%)$ & \multirow{2}{*}{$<0.001$} \\
\hline & & Positive & $185(14.4 \%)$ & $95(22.5 \%)$ & $90(10.4 \%)$ & \\
\hline & \multirow{2}{*}{ Milking maneuver } & Negative & $1169(90.8 \%)$ & $358(84.8 \%)$ & $811(93.4 \%)$ & \multirow{2}{*}{$<0.001$} \\
\hline & & Positive & $119(9.2 \%)$ & $64(15.2 \%)$ & $55(6.4 \%)$ & \\
\hline & \multirow{2}{*}{$\begin{array}{l}\text { Subacromial impingement } \\
\text { sign }\end{array}$} & Negative & 1207 (93.7\%) & $383(90.8 \%)$ & $824(95.1 \%)$ & \multirow{2}{*}{0.003} \\
\hline & & Positive & $81(6.3 \%)$ & $39(9.2 \%)$ & $42(4.9 \%)$ & \\
\hline & \multirow{2}{*}{ Posterior impingement sign } & Negative & $1121(87.0 \%)$ & $337(79.9 \%)$ & $784(90.5 \%)$ & \multirow{2}{*}{$<0.001$} \\
\hline & & Positive & $167(13.0 \%)$ & 85 (20.1\%) & $82(9.5 \%)$ & \\
\hline
\end{tabular}

MUCL: Medial ulnar corlateral ligamenent. 
Table 4. Age and position-adjusted odds ratio for the association between symptomatic TOS and upper extremity disorders.

\begin{tabular}{ccccc}
\hline & & $\begin{array}{c}\text { Odds } \\
\text { ratio }\end{array}$ & $\begin{array}{c}95 \% \text { confident } \\
\text { interval }\end{array}$ & P-value \\
\hline $\begin{array}{c}\text { Positive subjective } \\
\begin{array}{c}\text { symptoms during the } \\
\text { previous season }\end{array}\end{array}$ & Reccurence of shoulder/elbow pain & 2.38 & $1.87-3.04$ & $<0.001$ \\
& MUCL tenderness & 2.53 & $1.83-3.50$ & $<0.001$ \\
Abnormality of Physical & Milking maneuver & 2.63 & $1.78-3.91$ & $<0.001$ \\
findings & Subacromial impingement sign & 1.92 & $1.20-3.07$ & 0.007 \\
& Posterior impingement sign & 2.34 & $1.67-3.28$ & $<0.001$ \\
\hline
\end{tabular}

MUCL: Medial ulnar corlateral ligamenent.

According to the age and position-adjusted logistic regression analysis, subjects with symptomatic TOS were at significantly higher risk of shoulder and/or elbow pain (odds ratio [OR]: 1.96, 95\% confidence interval [CI]: 1.50 - 2.58) and had a higher recurrence rate of shoulder and/or elbow pain during the previous season (OR: 2.38 , 95\% CI: 1.87 - 3.04) compared with subjects without symptomatic TOS. As for physical findings, subjects with symptomatic TOS were also at significantly higher risk of MUCL tenderness (OR: 2.53, 95\% CI: $1.83-3.50$ ), positive milking maneuver, (OR: 2.63, 95\% CI: 1.78 - 3.91), positive subacromial impingement sign (OR: 1.92, 95\% CI: 1.20 - 3.07), and positive posterior impingement sign (OR: $2.34,95 \%$ CI: 1.67 - 3.28) compared to the subjects without symptomatic TOS (Table 4).

\section{Discussion}

It has been strongly suspected that neurovascular structures may be at high vulnerability to compression or stretching by throwing motions. Therefore, overhead-throwing athletes, especially baseball players, may be more be susceptible to the development of TOS.

During the late cocking and acceleration phases, the throwing shoulder is brought into abduction, extreme horizontal extension and external rotation with the scapula and clavicle in maximally retracted positions. At the costoclavicular space, the distance between the $1^{\text {st }}$ rib and clavicle decreased by nearly $50 \%$ when the arm moved from a neutral position to an ABER position [13] and the subclavian artery as being identified below the subclavius muscle [21] [37] [38].

Repetitive contraction and traction stress caused by the throwing motion may induce not only the hypertrophy of scalene muscles and pectoralis minor muscle, but also intramuscular hemorrhage and fibrosis, which could enhance compression of the neurovascular bundle at the inter-scalene triangle and subcoracoid space [4] [18] [39] [40] [41].

Stretching of the brachial plexus may also contribute to causing neuronal dysfunction. Furthermore, the strong traction force to the throwing arm during the deceleration and follow-through phases could put extreme traction stress on 
the neurovascular bundle. Abnormal posture of unilateral drooping, sagging, or sinking of the shoulder girdle, which is sometimes observed in the dominant side of overhead-throwing athletes, causes traction on the lower trunk of the brachial plexus against the first rib.

Our study revealed that about one-third (32.8\%) of high school baseball players are affected with symptomatic TOS. This is the first report to demonstrate the exact prevalence of TOS in baseball players, which is about three times more common than that in heavy industrial workers [32] [33] and 1.5 to three times more common to that in elite volleyball players [42]. Our results confirmed that baseball players might be at a higher risk of TOS compared with other overhead-throwing athletes.

Around $70 \%$ of baseball players who received $1^{\text {st }}$ rib resection for TOS complained of shoulder and/or elbow pain prior to surgery [43]. The current study also demonstrated that the prevalence of shoulder and/or elbow pain experiences and their recurrence rate were significantly higher in subjects with symptomatic TOS compared to those without. Furthermore, the incidence of MUCL tenderness, positive milking maneuver, and positive subacromial and posterior impingement sign were also higher in the symptomatic TOS group. The reason is believed to be that the compression of the brachial plexus at the thoracic outlet may disturb the axonal flow and induce disruption of the neurofilament architecture, which provokes the neuronal dysfunction and induces hypersensitivity of the involved upper extremity [44] [45]. This may exacerbate not only the nociceptive pain originating from the structural disorder of the shoulder and elbow joint, but also neuropathic pain attributed to entrapment peripheral nerve neuropathy (double crush syndrome). Therefore, it is important to take into account the involvement of TOS in upper extremity symptoms, especially when examining throwing athletes complaining of severe and/or prolonged upper extremity pain in excess of normal expectancy.

In the present study, about $40 \%$ of the subjects had bilateral symptoms induced by EAST regardless of past or present experience of neurological symptoms. One possible cause of bilateral symptoms could be congenital bilateral anatomical abnormalities such as cervical ribs, $1^{\text {st }}$ rib anomalies, vertebral anomalies, cervical muscle variants, and fibrous or muscular bands. It has been considered that most patients who suffer TOS have some anatomical predisposition, and in severe cases, impingement could occur at low functional levels [41]. Furushima et al. reported that subjects with severe TOS have some anatomical abnormalities of the origin and insertion of the scalene muscle, in which variation may cause compression within the interscalene triangle [46]. The other possible reason could be that bilateral hypertrophy of the scalene and pectoralis minor muscles induced by strenuous exercise is often observed in athletes [18] [39] [41]. The subclinical congenital and/or acquired anatomical pathology may be elicited neurovascular symptoms in the athletes when strenuously using their unilateral or bilateral arm in overhead activity.

There are several limitations in this study. The first is the insufficient criteria 
to diagnose TOS. Since the clinical presentation of this syndrome can be highly variable, this complex syndrome maybe difficult to diagnose, and an accurate diagnosis can only be made through detailed medical interviews and physical examinations. In the current study, symptomatic TOS was defined as the combination of positive EAST in the throwing arm, and previous experience of subjective neurovascular symptoms to make more precise diagnosis. However, these methods might still be insufficient because our study did not assess vascular TOS, which may have a more serious outcome with the potential of vascular compromise, and the involvement of peripheral nerve pathologies. More comprehensive and precise evaluation criteria should be established to make an accurate diagnosis of TOS. The second limitation is the design of our study. Since our study was a cross-sectional study, it was not possible to assess a causal relationship between TOS and upper extremity pain. It is necessary to conduct a prospective longitudinal study to confirm this relationship. The third limitation is that it may be insufficient to say that baseball players are at higher risk to develop TOS compared with the general population or athletes of other sports, because the criteria of TOS in previous studies was different from that of our study. Investigation into the prevalence of TOS in age and gender-matched control groups using the same criteria is required.

\section{Conclusion}

It is necessary to recognize that TOS is not a rare pathology in overhead-throwing athletes, especially baseball players, and players with symptomatic TOS are at a significantly higher risk of shoulder/elbow pain.

\section{Acknowledgements}

The authors thank and acknowledge the following people for their collaboration and assistance with this study: Tomohiko Shigihara, Hiroki Konno, Shuichi Onoda, Kazuhiro Endo, Takuya Shike, Shohei Nonobe, Takanori Kashimura, Yuichi Jumonji, Kazuhide Takada, Mai Kusano, Toshihisa Nishikata, Takehiro Tabe, Kenta Ono, Akihiro Ueno, and Ryo Ueda, belonging to the Fukushima Physical Therapy Association Medical Support Team.

\section{References}

[1] Peet, R., Henriksen, J., Anderson, T. and Martin, G. (1956) Thoracic Outlet Syndrome: Evaluation of a Therapeutic Exercise Program. Proceedings of the Staff Meetings. Mayo Clinic, 31, 281-287.

[2] Coote, H. (1861) Pressure on the Axillary Vessels and Nerve by an Exostosis from a Cervical Rib: Interference with the Circulation of the Arm, Removal of the Rib and Exostosis; Recovery. The Medical Times and Gazette, 2, 108.

[3] Keen, W. (1907) The Symptomatology, Diagnosis, and Surgical Treatment of Cervical Ribs. The American Journal of the Medical Journal Sciences, 133, 173. https://doi.org/10.1097/00000441-190702000-00001

[4] Stopford, J.S.B. and Telford, E.D. (1919) Compression of the Lower Trunk of the 
Brachial Plexus by a First Dorsal Rib with a Note on the Surgical Treatment. British Journal of Surgery, 7, 168. https://doi.org/10.1002/bjs.1800072604

[5] Tyson, R.R. and Kaplan, G.F. (1975) Modern Concepts of Diagnosis and Treatment of the Thoracic Outlet Syndrome. Orthopedic Clinics of North America, 6, 507-519.

[6] Wheeler, W.I. (1920) Compression Neuritis Due to the Normal First Dorsal Rib. Practitioner, 1, 65-72. https://doi.org/10.1007/BF02975271

[7] Atasoy, E. (2004) Thoracic Outlet Syndrome: Anatomy. Hand Clinics, 20, 7-14. https://doi.org/10.1016/S0749-0712(03)00078-7

[8] Brantigan, C.O. and Roos, D.B. (2004) Diagnosing Thoracic Outlet Syndrome. Hand Clinics, 20, 27-36. https://doi.org/10.1016/S0749-0712(03)00080-5

[9] Brantigan, C.O. and Roos, D.B. (2004) Etiology of Neurogenic Thoracic Outlet Syndrome. Hand Clinics, 20, 17-22. https://doi.org/10.1016/S0749-0712(03)00112-4

[10] Roos, D.B. (1976) Congenital Anomalies Associated with Thoracic Outlet Syndrome. Anatomy, Symptoms, Diagnosis, and Treatment. The American Journal of Surgery, 132, 771-778. https://doi.org/10.1016/0002-9610(76)90456-6

[11] Adson, A.W. and Coffey, J.R. (1927) Cervical Rib: A Method of Anterior Approach for Relief of Symptoms by Division of the Scalenus Anticus. Annals of Surgery, 85, 839-857. https://doi.org/10.1097/00000658-192785060-00005

[12] Ochsner, A., Gage, M. and DeBakey, M. (1935) Scalenus Anticus (Naffziger) Syndrome. The American Journal of Surgery, 28, 669-677. https://doi.org/10.1016/S0002-9610(35)90404-4

[13] Matsumura, J.S., Rilling, W.S., Pearce, W.H., Nemcek Jr, A.A., Vogelzang, R.L. and Yao, J.S. (1997) Helical Computed Tomography of the Normal Thoracic Outlet. Journal of Vascular Surgery, 26, 776-783. https://doi.org/10.1016/S0741-5214(97)70090-9

[14] Falconer, M.A. and Weddell, G. (1943) Costoclavicular Compression of the Subclavian Artery and Vein. Lancet, 2, 539-543. https://doi.org/10.1016/S0140-6736(00)72668-7

[15] Lewis, T., Pickering, G. (1934) Observations upon Maladies in Which the Blood Supply to Digits Ceases Intermittently or Permanently. Clinical Science, 1, 377.

[16] Wright, I.S. (1945) The Neurovascular Syndrome Produced by Hyperabduction of the Arms. American Heart Journal, 29, 1-19. https://doi.org/10.1016/0002-8703(45)90593-X

[17] Sanders, R.J. and Rao, N.M. (2007) Pectoralis Minor Obstruction of the Axillary Vein: Report of Six Patients. Journal of Vascular Surgery, 45, 1206-1211. https://doi.org/10.1016/j.jvs.2007.01.053

[18] Sanders, R.J., Rao, N.M. (2010) The Forgotten Pectoralis Minor Syndrome: 100 Operations for Pectoralis Minor Syndrome Alone or Accompanied by Neurogenic Thoracic Outlet Syndrome. Annals of Vascular Surgery, 24, 701-708. https://doi.org/10.1016/j.avsg.2010.02.022

[19] Karageanes, S.J. and Jacobs, A.W. (1998) Anomalous First Rib in a High School Wrestler. Clinical Journal of Sport Medicine, 8, 240-242. https://doi.org/10.1097/00042752-199807000-00015

[20] Katirji, B. and Hardy Jr., R.W. (1995) Classic Neurogenic Thoracic Outlet Syndrome in a Competitive Swimmer: A True Scalenus Anticus Syndrome. Muscle Nerve, 18, 229-233. https://doi.org/10.1002/mus.880180213

[21] Park, J.Y., Oh, K.S., Yoo, H.Y. and Lee, J.G. (2013) Case Report: Thoracic Outlet Syndrome in an Elite Archer in Full-Draw Position. Clinical Orthopaedics and Related Research, 471, 3056-3060. https://doi.org/10.1007/s11999-013-2865-2 
[22] Richardson, A.B. (1999) Thoracic Outlet Syndrome in Aquatic Athletes. Clinics in Sports Medicine, 18, 361-378. https://doi.org/10.1016/S0278-5919(05)70151-4

[23] Strukel, R.J., Garrick, J.G. (1978) Thoracic Outlet Compression in Athletes a Report of Four Cases. American Journal of Sports Medicine, 6, 35-39. https://doi.org/10.1177/036354657800600201

[24] Coker, W.L. (2013) Baseball Injuries: Case Studies, by Type, in the Major Leagues. MacFarland Company, Inc., Jefferson.

[25] Tullos, H.S., Erwin, W.D., Woods, G.W., Wukasch, D.C., Cooley, D.A. and King, J.W. (1972) Unusual Lesions of the Pitching Arm. Clinical Orthopaedics and Related Research, 88, 169-182. https://doi.org/10.1097/00003086-197210000-00029

[26] Melby, S.J., Vedantham, S., Narra, V.R., Paletta Jr., G.A., Khoo-Summers, L., Driskill, M. and Thompson, R.W. (2008) Comprehensive Surgical Management of the Competitive Athlete with Effort Thrombosis of the Subclavian Vein (Paget-Schroetter Syndrome). Journal of Vascular Surgery, 47, 809-820. https://doi.org/10.1016/j.jvs.2007.10.057

[27] Cordobes-Gual, J., Lozano-Vilardell, P., Torreguitart-Mirada, N., Lara-Hernandez, R., Riera-Vazquez, R. and Julia-Montoya, J. (2008) Prospective Study of the Functional Recovery after Surgery for Thoracic Outlet Syndrome. European Journal of Vascular and Endovascular Surgery, 35, 79-83. https://doi.org/10.1016/j.ejvs.2007.07.013

[28] Hempel, G.K., Shutz, W.P., Anderson, J.F. and Bukhari, H.I. (1996) 770 Consecutive Supraclavicular First Rib Resections for Thoracic Outlet Syndrome. Annals of Vascular Surgery, 10, 456-463. https://doi.org/10.1007/BF02000592

[29] Sanders, R.J. and Haug, C. (1991) Review of Arterial Thoracic Outlet Syndrome with Report of Five New Instances. Surgery, Gynecology \& Obstetrics, 173, 415-422.

[30] Safran, M.R. (2004) Nerve Injury about the Shoulder in Athletes, Part 2: Long Thoracic Nerve, Spinal Accessory Nerve, Burners/Stingers, Thoracic Outlet Syndrome. American Journal of Sports Medicine, 32, 1063-1076. https://doi.org/10.1177/0363546504265193

[31] Wood, V. and Biondi, J. (1990) Double Crush Nerve Compression in Thoracic Outlet Syndrome. Journal of Bone \& Joint Surgery, 72A, 85-87. https://doi.org/10.2106/00004623-199072010-00014

[32] Sällström, J. and Schmidt, H. (1984) Cervicobrachial Disorders in Certain Occupations, with Special Reference to Compression in the Thoracic Outlet. American Journal of Industrial Medicine, 6, 45-52. https://doi.org/10.1002/ajim.4700060107

[33] Sällström, J. and Thulesius, O. (1982) Non-Invasive Investigation of Vascular Compression in Patients with Thoracic Outlet Syndrome. Clinical Physiology, 2, 117-125. https://doi.org/10.1111/j.1475-097X.1982.tb00014.x

[34] Twaij, H., Rolls, A., Sinisi, M. and Weiler, R. (2013) Thoracic Outlet Syndromes in Sport: A Practical Review in the Face of Limited Evidence-Unusual Pain Presentation in an Athlete. British Journal of Sports Medicine, 47, 1080-1084. https://doi.org/10.1136/bjsports-2013-093002

[35] Jobe, F.W. (2000) Diagnosis and Treatment of Collateral Ligament in Athletes. In: Morrey, B.F., Ed., The Elbow and Its Disorders, 3rd Edition, Saunders, Philadelphia, 549-555.

[36] Meister, K. (2000) Internal Impingement in the Shoulder of the Overhand Athlete: Pathophysiology, Diagnosis, and Treatment. American Journal of Orthopedics, 29, 433-438. 
[37] Remy-Jardin, M., Doyen, J., Remy, J., Artaud, D., Fribourg, M. and Duhamel, A. (1997) Functional Anatomy of the Thoracic Outlet: Evaluation with Spiral CT. Radiology, 205, 843-851. https://doi.org/10.1148/radiology.205.3.9393546

[38] Remy-Jardin, M., Remy, J., Masson, P., Bonnel, F., Debatselier, P., Vinckier, L. and Duhamel, A. (2000) Helical CT Angiography of Thoracic Outlet Syndrome: Functional Anatomy. American Journal of Roentgenology, 174, 1667-1674. https://doi.org/10.2214/ajr.174.6.1741667

[39] King, J.W., Brelsford, H.J. and Tullos, H.S. (1969) Analysis of the Pitching Arm of the Professional Baseball Pitcher. Clinical Orthopaedics and Related Research, 67, 116-123. https://doi.org/10.1097/00003086-196911000-00018

[40] McCarthy, W.J., Yao, J.S., Schafer, M.F., Nuber, G., Flinn, W.R., Blackburn, D. and Suker, J.R. (1989) Upper Extremity Arterial Injury in Athletes. Journal of Vascular Surgery, 9, 317-327. https://doi.org/10.1016/0741-5214(89)90052-9

[41] Stammers, F.A. (1950) Pain in the Upper Limb from Mechanisms in the Costoclavicular Space. Lancet, 1, 603-607. https://doi.org/10.1016/S0140-6736(50)90505-8

[42] van de Pol, D., Kuijer, P.P., Langenhorst, T. and Maas, M. (2012) High Prevalence of Self-Reported Symptoms of Digital Ischemia in Elite Male Volleyball Players in the Netherlands: A Cross-Sectional National Survey. American Journal of Sports Medicine, 40, 2296-2302. https://doi.org/10.1177/0363546512456973

[43] Otoshi, K., Furushima, K., Tsujino, A. and Itoh, Y. (2011) Clinical Aspect of Thoracic Outlet Syndrome in Baseball Players and Its Surgical Results. Jpn.J.Orthop. Sports Med, 31, 142-148. [In Japanese]

[44] Osterman, A.L. (1988) The Double Crush Syndrome. Orthopedic Clinics of North America, 19, 147-155.

[45] Upton, A.R. and McComas, A.J. (1973) The Double Crush in Nerve Entrapment Syndromes. Lancet, 2, 359-362. https://doi.org/10.1016/S0140-6736(73)93196-6

[46] Furushima, K., Koga, R., Iwabu, S., Yamamoto, Y., Itoh, Y., Mitsui, Y., Goto, M. and Otoshi, K. (2015) Usefulness of Endoscopic Assisted Trans-Axillary 1st Rib Resection for the Treatment of Thoracic Outlet Syndrome in Baseball Players. Katakansetsu. 39, 777-782. [In Japanese]

\section{Scientific Research Publishing}

Submit or recommend next manuscript to SCIRP and we will provide best service for you:

Accepting pre-submission inquiries through Email, Facebook, LinkedIn, Twitter, etc. A wide selection of journals (inclusive of 9 subjects, more than 200 journals)

Providing 24-hour high-quality service

User-friendly online submission system

Fair and swift peer-review system

Efficient typesetting and proofreading procedure

Display of the result of downloads and visits, as well as the number of cited articles

Maximum dissemination of your research work

Submit your manuscript at: http://papersubmission.scirp.org/

Or contact health@scirp.org 